\title{
Using ISOS consensus test protocols for development of quantitative life test models in ageing of organic solar cells
}

Kettle, J.; Stoichkov, V.; Kumar, D.; Corazza, M.; Gevorgyan, S. A.; Krebs, F. C.

Published in:

Solar Energy Materials and Solar Cells

Link to article, DOI:

10.1016/j.solmat.2017.04.005

Publication date:

2017

Document Version

Peer reviewed version

Link back to DTU Orbit

Citation (APA):

Kettle, J., Stoichkov, V., Kumar, D., Corazza, M., Gevorgyan, S. A., \& Krebs, F. C. (2017). Using ISOS

consensus test protocols for development of quantitative life test models in ageing of organic solar cells. Solar Energy Materials and Solar Cells, 167, 53-59. https://doi.org/10.1016/j.solmat.2017.04.005

\section{General rights}

Copyright and moral rights for the publications made accessible in the public portal are retained by the authors and/or other copyright owners and it is a condition of accessing publications that users recognise and abide by the legal requirements associated with these rights.

- Users may download and print one copy of any publication from the public portal for the purpose of private study or research.

- You may not further distribute the material or use it for any profit-making activity or commercial gain

- You may freely distribute the URL identifying the publication in the public portal 
Using ISOS consensus test protocols for development of quantitative life test models in ageing of organic solar cells

Kettle, Jeffrey; Stoichkov, Vasil; Kumar, Dinesh; Corazza, M.; Gevorgyan, S.A.; Krebs, F.C.

\section{Solar Energy Materials and Solar Cells}

DOI:

10.1016/j.solmat.2017.04.005

Published: 01/08/2017

Peer reviewed version

Cyswllt i'r cyhoeddiad / Link to publication

Dyfyniad o'r fersiwn a gyhoeddwyd / Citation for published version (APA):

Kettle, J., Stoichkov, V., Kumar, D., Corazza, M., Gevorgyan, S. A., \& Krebs, F. C. (2017). Using ISOS consensus test protocols for development of quantitative life test models in ageing of organic solar cells. Solar Energy Materials and Solar Cells, 167, 53-59. DOI: 10.1016/j.solmat.2017.04.005

\footnotetext{
Hawliau Cyffredinol / General rights

Copyright and moral rights for the publications made accessible in the public portal are retained by the authors and/or other copyright owners and it is a condition of accessing publications that users recognise and abide by the legal requirements associated with these rights.

- Users may download and print one copy of any publication from the public portal for the purpose of private study or research.

- You may not further distribute the material or use it for any profit-making activity or commercial gain

- You may freely distribute the URL identifying the publication in the public portal ?
}

Take down policy

If you believe that this document breaches copyright please contact us providing details, and we will remove access to the work immediately and investigate your claim. 


\title{
Using ISOS consensus test protocols for development of quantitative life test models in ageing of organic solar cells
}

\author{
J. Kettle ${ }^{1}$, V. Stoichkov' ${ }^{1}$, D. Kumar ${ }^{1}$, M. Corazza², S. A. Gevorgyan², F. C. Krebs² \\ ${ }^{1}$ School of Electronic Engineering, Bangor University, Dean St, Gwynedd, Bangor, LL57 1UT, Wales, \\ UK.E-mail: j.kettle@bangor.ac.uk \\ ${ }^{2}$ Department of Energy Conversion and Storage, Technical University of Denmark, Frederiksborgvej \\ 399, DK-4000 Roskilde, Denmark
}

\begin{abstract}
As Organic Photovoltaic (OPV) development matures, the demand grows for rapid characterisation of degradation and application of Quantitative Accelerated Life Tests (QALT) models to predict and improve reliability. To date, most accelerated testing on OPVs has been conducted using ISOS consensus standards. This paper identifies some of the problems in using and interpreting the results for predicting ageing based upon ISOS consensus standard test data. Design of Experiments (DOE) in conjunction with data from ISOS consensus standards are used as the basis for developing life test models for OPV modules. This is used to study their temperature-humidity and light-induced degradation, which enables failure rates during accelerated testing to be assessed against the typical outdoor operational conditions. The life test models are used to assess the relative severity of the ISOS standards and the impact of geographic and seasonal climatic changes on OPV degradation.
\end{abstract}

Keywords: Organic solar cells, OPV, stability of OPVs

\section{Introduction}

Organic Photovoltaics (OPVs) have matured as an energy harvesting and generation technology over the past 2 to 3 years, with the number of commercial products currently available [1,2]. Stability and accelerated testing remains a critical issue for researchers and industrialists alike. Normally Accelerated Life Testing (ALT) is needed at various stage of a product development cycle, for example, when identifying optimal material sets [3], providing relative comparisons of module stability [4] and also information on the products failure mechanisms [5]. However, as OPV's are applied in more commercial applications there is a greater need in order to predict the expected life in outdoor operation. Longer term, companies trying to commercialise this technology would also need predictive ageing models in order to estimate warranty provisions. To date, the most commonly used strategies for relating outdoor degradation to indoor accelerated testing are the use of meta data analysis [6] and round robins experiments $[7,8]$. An alternative technique is to use life test models based upon quantitative accelerated to address lifetime and try to quantify the 
degradation through the application of a mathematical model, which has been explored by Halliant $[9,10]$ for light induced degradation.

Most ALT testing in the literature is based upon ISOS consensus standards, defined by Reese et al [11]. Apart from a few notable examples, testing tends to be done using small sample sets and single levels of stress or a maximum two stresses. ISOS consensus standards are qualitative tests and do not quantify the life characteristics of an OPV under normal operating conditions. However, they do provide some useful information into the types and degree of stress needed for subsequent quantitative test. The primary benefit of undertaking ISOS tests is to enable relative comparisons of OPV modules and initial assessment of failure mechanisms, so that stability can be fed back in order to eliminate the causes of failure in future designs $[12,13]$.

In this paper, ISOS consensus standards are used as the basis for developing life test models for OPV modules, which enables failure rates during ALT to be assessed against the operational conditions and subsequent degradation that OPVs will experience under such outdoor conditions. To do this, large data sets are needed and therefore initial data for life test models has been extracted from previous large module testing undertaken by Corazza et al. [14] Where necessary, additional experiments have been conducted to improve the life test model and enable more accurate life prediction.

\section{Experimental}

\subsection{Data acquisition}

All testing was done using the 'InfinityPV' mini- module [15]. Indoor ALT data has been acquired by both the Danish Technical University (DTU) and Bangor University (BU). The initial PCE performance of the solar cells is listed in SI-2. In DTU, a thermal humidity chamber from Thermotron was used for all temperature and humidity (e.g. ISOS-D) testing. A QUV 'Q-Sun' test chamber or metal halide was used for all light degradation studies (i.e. ISOS-L-3 and ISOS-L-2, respectively). 3). In BU, a Weiss UK testing chamber was used for thermal humidity. For light degradation analysis, either sulphur plasma lamp or halogen light soaker was used (GB Sol Itd, Taffs Well, Wales, UK). The number of modules used for each test are stated in SI-1.

To fit life test models to ISOS standard testing data, either in-situ degradation data or 'time to failure' needs to be defined. For this paper we study degradation to $80 \%$ or $50 \%$ of the original maximum efficiency value (i.e. T80\% or T50\%).

\section{$\underline{2.2 \text { Data analysis }}$}


All data acquisition was acquired automatically and quantified using a C++ program. Data was uploaded to an internal MS access database with time stamping, module ID, test conditions and time to failure characterised. Data was analysed using a number of commercial reliability and statistical software packages. To summarise our procedure, a probability distribution function (PDF) was selected initially. In addition, a life time model was selected which most accurately modelled life degradation characteristics from literature. Both the PDF fitting parameters and life model fitting parameters were optimised using maximum likelihood estimation (MLE), so that the best fit is obtained for the particular life model. Based upon the parameters extracted from the life model, the simulation of OPV stability can be conducted at the 'operational' stress, which is a reduced level to the accelerated conditions, but correlates to the conditions the OPV is likely to experience in the field. Operational stress was calculated using weather station data from a Davis Inc. 'Vantage pro' weather station and calibrated silicon reference cell from IMT-solar GmbH located on the roof of the School of electronic engineering, Bangor University, Wales, UK (latitude and longitude of 53.2280N, $4.1280 \mathrm{~W}$, respectively), previously reported $[16,17]$. All data collection and analysis was done using in-house developed software, Minitab or Reliasoft.

For all data fitting in this paper, a 2-point Weibull PDF was used as shown in equation 1, where $\beta$ is defined as the shape parameter, $\eta$ is the scale parameter, $\mathrm{t}$ is the time and $f(t)$ is the probability of failure.

$\mathrm{f}(\mathrm{t})=\frac{\beta}{\eta}\left(\frac{t}{\eta}\right)^{\beta-1} e^{-\left(\frac{t}{\eta}\right)^{\beta}}$ Equation 1

To compare modelled data to the data obtained in outdoor experiments, a consistent definition of failures needed. For this work, we have used the life test model to calculate time for $63 \%$ of the population of OPV modules tested have declined a particular value [such as $80 \%$ of the original value (T80\%) or $50 \%$ of the original value (T50\%)]. This value is defined is often referred to as $\mathrm{B}(63 \%)$. By considering equation 1 , when $t=\eta$, the cumulative number of failures in the population, $F(t)=$ $63 \%$, so $\eta$ is equivalent to $B(63 \%)$.

To compare experimental to simulated, outdoor failure times are calculated from when approximately $63 \%$ of the modules have reached the failure time (e.g. T80\% or T50\%). To compare the regression line fitting, the correlation coefficient, $\rho(R h o)$, has been obtained for all datasets to measure how well the linear correlation fits the data. 


\subsection{Datasets used for life test model fitting}

\subsubsection{Temperature-humidity analysis}

For temperature humidity (T-H) analysis, four sets of data fitting was undertaken. Dataset 1-D consisted of DTU experiment previously reported in [14] using only ISOS consensus standard testing (ISOS D-1, -2 and -3). For this dataset multiple sample types are used, including spin coated small samples, samples from a Mini Roll Coater and R2R-processed modules. The initial distribution of performance of these are shown in SI-2. For Dataset 2-D, the aforementioned dataset is filtered so that only R2R modules were used for the data analysis. Dataset 3-D used all of the data from Dataset 2 but included an additional experiment undertaken at Bangor University where modules were subjected to an additional low temperature and high humidity test at $318 \mathrm{~K} / 85 \%$. Finally, for Dataset 4-D, a ( $\left.2^{\wedge} 2\right)$ full factorial design was undertaken at Bangor University using the following conditions; $318 \mathrm{~K} / 65 \%, 318 \mathrm{~K} / 85 \%, 338 \mathrm{~K} / 65 \%$ and $338 \mathrm{~K} / 85 \%$. During analysis, data from outdoor test 1 was fed back into the datasets for improved regression line fitting of the life test model.

\subsubsection{Light degradation analysis}

For light degradation analysis, five sets of data fitting were undertaken. Dataset $1-L$ consisted of DTU experiment previously reported in [14] using only ISOS consensus standard testing (ISOS D-2 and ISOS L-2, -3). Therefore, two different light levels were used for data fitting (0 sun and 1 Sun), and multiple sample types were used (spin coated, mini roll coated and R2R samples). For Dataset 2-L, the previous dataset is filtered so that only R2R modules were used for the data analysis. Dataset 3-L uses all data from Datasets 2-L and 4-L. For Dataset 4, four experiments were conducted with a variety of irradiance levels ( 2 Sun, 1 sun, 0.5 Sun and 0.25 Sun) and using a sulphur plasma lamp for module irradiation. Dataset 5-L was also conducted with a variety of irradiance levels ( 1 sun, 0.5 Sun and 0.25 Sun), but a using a halogen light soaker.

\subsection{Model verification}

In order to verify the life test models, outdoor module stability data has been acquired at Bangor University to compare stability of modules under real-life conditions to the stability simulated from a life test model. Four sets of outdoor data analysis have been used for this work using similar modules.

In order to study the effect of only temperature and humidity on the degradation, one set of OPV modules were placed outside but were covered with a steel sheet to prevent any light entering the $\mathrm{OPV}$; therefore, the degradation should only be due to temperature and humidity affects (assuming 
thermal cycle and condensation has a minimal effect). This test was conducted from January 2017, and is shown in table 1 as outdoor test number 1.

In addition, three outdoor tests were undertaken when no covering of the solar cell was undertaken, shown as outdoor test number 2,3 and 4 in table 1. Data is shown for the environmental conditions (irradiance, $\mathrm{RH}$ and temperature) during these tests for the time taken for each set of data to reach $B(63 \%)$.

\section{Results}

\subsection{Temperature-humidity analysis}

For thermal humidity analysis, a modified Arrhenius equation was used was used for predicting life at operational conditions, as shown in equation 2 where life is shown as a function of temperature $(V)$ and humidity $(H)$ and $\mathrm{A}, \mathrm{B}$ and $\varnothing$ are all fitting parameters. For this analysis, the operational stress (i.e. temperature and humidity that the OPV experience in the field is $289 \mathrm{~K} / 76 \%$ (May average in Bangor, Wales, 2016)

$\mathrm{L}(\mathrm{V}, \mathrm{H})=A e^{\frac{\emptyset}{V}+\frac{b}{H}}$

Equation 2

$A_{F}=\frac{L_{U S E}}{L_{\text {Accelerated }}}=\frac{A e^{-\left(\frac{\emptyset}{V_{O}}+\frac{b}{H_{O}}\right)}}{A e^{-\left(\frac{\varnothing}{V_{A}}+\frac{b}{H_{A}}\right)}}=e^{\varnothing\left(\frac{1}{V_{O}}-\frac{1}{V_{A}}\right)+b\left(\frac{1}{H_{O}}-\frac{1}{H_{A}}\right)}$

Equation 3

Based upon equation 2, life is function of two stress conditions, so life versus temperature and life versus Relative Humidity $(\mathrm{RH})$ can be plotted on a logarithmic scale to show how varying temperature or humidity affects the life of the OPV, whilst the other variable is kept constant. This is shown in figure 1(a) and 1(b) for life model fittings from Dataset 4-D. During analysis, data from outdoor test 1 was also used to improve the regression line fitting of the life test model An important characteristic often assessed in life test models is the acceleration factor (AF), which shows the ratio of the OPVs life at the operational stress level to its life at an accelerated stress level and is defined in equation 3 where $V_{O}$ and $V_{A}$ is the temperature at operational stress and accelerated stress, respectively and $H_{O}$ and $H_{A}$ is the $\mathrm{RH}$ at 'use' stress and accelerated $\mathrm{RH}$, respectively. Shown in figure 1 (c) is AF versus temperature and AF versus $\mathrm{RH}$, whilst the other stress is kept constant. It is interesting to see that at low levels of $\mathrm{RH}$ (when $\mathrm{RH}<40 \%$ ), the $\mathrm{AF}$ is less than 0.1 and humidity therefore has a small effect upon the OPV degradation. 
Shown in table 2 is a summary of Weibull PDF and Life test model fitting parameters for Datasets 14-D. Shown are the fitted parameters for $\beta$ (the shape parameters in a Weibull 2-P PDF), $\eta$ (the scale parameters in a Weibull 2-P PDF) and B and $\emptyset$, which are both fitting parameters for the life test model in Equation 2. An important conclusion from Table 2 is the fitting parameters are dependent on module type (e.g. comparing data 1-D \& 2-D) and tester (2-D \&3/4-D. Therefore, there will be no 'golden model' that applies to all module types and even testing locations.

The fitting parameters provide valuable insight in to the stability of OPVs. For all data, $\beta>1$ and indicates that the failure rate of OPVs (e.g. failures per unit time), increases as time increases. This implies that the failures in the InfinityPV OPV modules are drive by 'wear-out' rather than suffering from early life failures. This is could be perceived positively as early life failures, tend to indicate that problems occurring during the manufacturing, or poor product design. However, as OPV modules are wearing out within a couple of hundred hours, the data implies OPV active materials and encapsulation strategies are intrinsically unstable. The other PDF fitting parameters is $\eta$, the scale parameter and as mentioned in section 2.2, the value of $\eta$ enables direct comparison between experimental data in table 1 and predicted life from the life test models. From experimental data, (obtained May-July 2016 and shown in table 1), $\eta=480$ hours and therefore the value of the simulated value of $\eta$ from dataset 2-, 3- and 4-D match experimental values within a factor of 2 .

It is difficult to conclude which is the 'best' dataset for data fitting of the Temperature-Humidity model. The fitted parameters for Dataset 2-, 3- and 4-D provide the closest simulated lifetime experimentally obtained outdoor data, by comparing the value of simulated to experimental values of $\eta$ in table 2. However, Dataset 2-D doesn't show life is particularly sensitive to variations in temperature or $\mathrm{RH}$ (when considering the ratios of $\mathrm{B} / \mathrm{H}$ and $\varnothing / \mathrm{V}$. The fitted data from Dataset 4-D overestimates the value of $\eta$. However, this can be viewed positively because the life should be overestimated at this point. This is because the model only considers degradation due to temperature-humidity effects, but the degradation observed in the OPV modules in Table 1 (test 1) include other factors that such as thermal changes and condensation. It is therefore reasonable to assume that the fitted values for Dataset 4-D represent conservative, but realistic fitted value for the temperature-humidity model

Finally, inspection of the $\emptyset$ enables a comparison of the effect that temperature has on the life, and $B$ a measure of the effect that $R H$ has on the life. By inspection of the ratios $\varnothing / V$ and $B / H$, insight into the greater susceptibility of an OPV to either temperature and humidity degradation can be deduced. If one ratio is lower, the corresponding stress has a lower impact on the life of an OPV. Using Dataset 1-D (ISOS standard testing), it can be seen that just increasing temperature has limited 
effect on lifetime of an OPV $(\varnothing / V<</ H)$. However, this conclusion appears misleading and is likely to be as result of a poorly designed experiment, as there is no low temperature and high humidity test undertaken in Dataset 1- or 2-D. If additional data is added to the analysis (at the stress level $289 \mathrm{~K} / 85 \%$ ), as in the case of Dataset 3-D, it is evident that temperature that plays the bigger role in causing the degradation. This probably indicates the failure mechanisms caused by humidity, are themselves accelerated by the temperature.

\subsection{Light degradation analysis using the Inverse Power law (IPL)}

The inverse power law (IPL) model is commonly used for non-thermal accelerated stresses (such as light) and is given by equation 4 , where $K$ and $n$ are fitting parameters and $I$ is the irradiance in $\mathrm{mW} / \mathrm{cm}^{2}$. Five datasets were used for fitting to the IPL model in equation 4 and the data is shown in Table 3. It is worth noting that three different light sources were used for these tests; Dataset 1-L and 2-L used QUV test chambers, Dataset 3-L and 4-L used a sulphur plasma lamp light soaker and Dataset 5 used a halogen light soaker. As such, the spectrum varied as a function of test.

Shown in figure 2 is the life versus irradiance level for Dataset 5-L. As expected, it is clear that higher irradiances lead to shorter lifetimes. Figure 2 shows the AF as a function of irradiance level and a sub-linear relationship is evident. This is supported by Table 3, where the fitting parameter, $n<1$ (for all datasets), which shows that AF has a sub-linear variation with irradiance level. This result is particular significant result for those undertake high concentrated light experiments, as it is evident for increasing light levels, the degradation has a lesser and lesser impact on light induced degradation.

When comparing the value of simulated $\eta$ (table 3 - calculated from irradiance levels in June 2014) versus experimental, it is clear that Dataset 5-L provides the closest match. This was undertaken with a halogen light soaker, which possesses low spectral irradiation in the UV region, but it's possible this spectral light source provides the closest match to the outdoor conditions expected in Bangor, which experiences a low UV index due to the high latitude and high proportion of diffuse irradiation. The worst match is derived from the sulphur plasma lamp (Dataset 4-L), which aggressively degrades modules due to the high temperatures, resulting in a significant under prediction of outdoor stability.

Using the fitting parameters from dataset 5-L, further model verification can be achieved by using the other outdoor tests described in table 1 and is summarised in table 4. In addition to dataset 5-L, dataset 6 contains the fitting parameters for the time taken for the life of the modules to reach T50\%. For data obtained in $2014-2015$, the simulated data from the IPL law predicts the 
experimental value of $\eta$ to within $20 \%$ accuracy. The modules measured June 2016 exhibit a quicker degradation to $\mathrm{T} 80 \%$, followed by a stable period of operation between $\mathrm{T} 80 \%$ and $\mathrm{T} 50 \%$, so the simulated data does not predict the ageing at later times quite so accurately.

$$
\begin{array}{ll}
L(I)=\frac{1}{K I^{n}} & \text { Equation } 4 \\
A_{F}=\frac{L_{U S E}}{L_{\text {Accelerated }}}=\frac{\frac{1}{K I_{O}^{n}}}{\frac{1}{K I_{A}^{n}}}=\left(\frac{I_{A}}{I_{O}}\right)^{n} & \text { Equation 5 }
\end{array}
$$

\subsection{Light degradation analysis using the Temperature-Light (TL) model}

One of the limitations of the light soaking tests for predictive ageing is that data is normally obtained at elevated temperature (typically $55^{\circ} \mathrm{C}$ ), so the data obtained in section 3.2 is a convolution of light and temperature. When temperature and a second stress (i.e. light) are the accelerated stresses of a test, then a modified Eyring model can be applied as a life test mode, as shown in equation 6 , and is referred to as the Temperature-Light (TL) relationship can be applied, with the acceleration factor defined in equation 7. In equation 6 and 7 , the values $C, D$ and $n$ are fitting parameters and $V$ and $I$ are the variables, Temperature (in $\mathrm{K}$ ) and Irradiance (in $\mathrm{W} / \mathrm{m}^{2}$ ), respectively. To undertake this analysis, a $\left(2^{\wedge} 2\right)$ full factorial design was undertaken using the following conditions; 0.25 Sun/318K, 0.25 Sun/338K, 0.5 Sun/318K and 0.5 Sun/338K. Shown in Table 5 are the fitting parameters of the TL model, which have been calculated using failure times of both $\mathrm{T} 80 \%$ and $\mathrm{T} 50 \%$.

The results for the TL model also shown in table 4. When comparing to the outdoor measurement campaigns, the TL model seems to provide a worse prediction of $\mathrm{T} 80 \%$ and $\mathrm{T} 50 \%$ times than the simulated data from the IPL model. However, it provides a much more reasoned approach to light induced degradation analysis and could be a better alternative for predicting degradation in different climates, where ambient temperatures are more likely to fluctuate than in the UK.

$$
\begin{aligned}
& L(I, V)=\frac{C}{I^{n} e^{-\frac{D}{V}}} \\
& A_{F}=\frac{L_{U S E}}{L_{\text {Accelerated }}}=\frac{I_{A}{ }^{n}}{I_{O}} e^{D\left(\frac{1}{V_{O}}-\frac{1}{V_{A}}\right)}
\end{aligned}
$$

\section{Analysis using the life test models}




\subsection{Assessment of the severity of ISOS standard testing}

The data obtained in section 3 can be used to assess relative severity of ISOS consensus standards. Table 6 shows the AF for the ISOS D- and L consensus standards. Based on each ISOS test, hours to simulate 1 calendar year outdoor degradation was calculated based on median weather data during June 2014 in Bangor, North Wales.

Considering the ISOS D- data first of all; ISOS D-1 shows an $A F<1$, indicating that testing under this condition should reduce the degradation relative to outdoor degradation, which is not surprising as this test is referred to as a 'shelf life' test. However, by increasing the temperature (ISOS D-2) and the temperature and humidity (ISOS D-3), the $A F$ exceeds one, indicating increased degradation relative to the degradation expected during outdoor testing. ISOS D-3 testing shows an AF of 12, and indicates that $\approx 717$ hours under these conditions will accelerate the degradation enough to simulate 1 year of outdoor testing. The calculations of ISOS L- tests were conducted TL model. In both the ISOS-L-2 and ISOS-L-3 tests, the $A F$ was 16 and 25 when compared to environmental conditions in June 2014 in Bangor, North Wales, respectively. Based upon these values, test hours to simulate a full year outdoor performance shown in table 6 .

In practice, the OPVs will not experience steady values of temperature, humidity or light, and exposure to the highest rated values is limited in time with daily and seasonal variations. Testing to meet the higher values of test hours would provide additional margin for the translation of the test results to one year of operational conditions.

\subsection{Comparison of relative stability of modules in different climates}

Based on the reliability calculations, it is clear that temperature, humidity and light are main drivers of OPV aging. As a broad assessment the IPL and temperature-humidity model can be combined by considering the equations for the $\mathrm{AF}$ as described in equations 3 and 5 , as shown in equation 8 . The main assumption in doing this is that light and temperature humidity each of these stresses induce different degradation mechanisms and these are independent of each other. Whilst this assumption potentially has some flaws, it does provide a mechanism to enable comparison of OPV degradation in different climatic conditions by using the fitting parameters as defined tables 2 and 3 for dataset 4 and 5 , respectively

$A_{F}=e^{\emptyset\left(\frac{1}{V_{O}}-\frac{1}{V_{A}}\right)+B\left(\frac{1}{H_{O}}-\frac{1}{U_{A}}\right)} \cdot\left(\frac{I_{A}}{I_{O}}\right)^{n} \quad$ Equation 8

Shown in table 7 is the experimentally calculated values of time for $63 \%$ of the modules to have reached $\mathrm{T} 80 \%$ in different climates, relative to the degradation observed in Bangor, Wales, UK in 
June 2014. Data for Madrid, Rio de Janeiro and wintertime in Bangor was calculated from historic weather data. In the case of Madrid, in spite of the higher temperatures and irradiance levels, due to the lower $\mathrm{RH}$, the $A F<1$; indicating that the degradation in Madrid should be lower than that of Bangor. OPVs are also predicted to be more stable in wintertime in Bangor; due to the lower temperature and irradiance during wintertime, the $A F<1$. Measured experimental data obtained from outdoor testing is supportive of this claim, providing some confidence in this approach for predicting stability in different climates.

\subsection{Consideration of how climatic conditions affect annual degradation rates}

The life test models can be used to assess how seasonal changes in environmental conditions affect the solar cell degradation. Shown in figure 3 is the changes in average daily temperature, $\mathrm{RH}$ and irradiance over a calendar year in Bangor, Wales. The UK is an oceanic climate and experiences relatively cool summers and cool winters and a relatively narrow annual temperature range and few extremes of temperature. Average irradiance levels are low in wintertime due to the short days and a factor $4-5 x$ greater in Summertime. By contrast, the RH is greatest in wintertime, due to the high precipitation levels.

Shown in figure 3 is how light-temperature and temperature-RH models predict degradation over the course of the year, based upon time to reach $180 \%$. The changes in degradation as a result of temperature- $\mathrm{RH}$ changes over the course of the year is relatively low, and can be equated to the relatively narrow range of temperature and $\mathrm{RH}$ changes over the course of the year. By contrast, significant variation in light degradation is observed from the TL model as a function of month. Based upon the data in figure 3 , it is reasonable to assume that during winter, degradation in OPV modules is driven by humidity-related effects such as corrosion. By contrast, in summertime, the degradation of modules seems to be driven primarily by light related effects, but humidity-related degradation continues to play a significant role. As a result of the data in figure 3 , it is also reasonable to conclude that degradation of modules in wintertime will be less than in summertime.

\section{Conclusion}

The application of life test models to ALT data for OPV modules has been reported. Life test models relate degradation at an elevated stress level to that of the much lower level. The relationship between operational life and temperature-humidity and temperature-light has been modelled and simulated data has been compared against experimental data. The life tests models have been used 
for reviewing the severity of existing standard ISOS test protocols and predicting relative stability of modules in different climates and seasons. It is worth considering the limitations of this work and where future work should be concentrated. Outdoor conditions are constantly changing so no PV will experience different stresses and different levels of stress depending upon the time of day, month and year. Therefore, time varying stress and multi-stress analysis are needed for more accurate and bespoke model development.

Thermal cycling is likely to have an impact upon long-term stability of OPVs. This stress factor should be considered more comprehensively when the stability of OPVs increases beyond 1 year and more accurate predictive ageing of OPV modules is required. Over the relatively short lifetime of these modules, it is unlikely to have a significant impact. Data shown in $\mathrm{SI}-3$ to show how thermal changes in a test chamber affect the stability of OPV modules (in accordance with ISOS-T3). Compared to light and humidity-induced degradation, it appears to have a relatively minor effect. However more detailed study is required to accurately assess this degradation and relate this to outdoor ageing experiments.

\section{Acknowledgement}

Vasil Stoichkov would like to thank the Sêr Cymru National Research Network for funding of his PhD studies

\section{$\underline{\text { References }}$}

[1] F.C. Krebs, J. Fyenbo, D. M. Tanenbaum, S. A. Gevorgyan, R. Andriessen, B. van Remoortere, Yulia Galagan, and Mikkel Jørgensen, The OE-A OPV demonstrator anno domini 2011, Energy \& Environmental Science 4, no. 10 (2011), 4116-4123.

[2] See infinityPV 'HeLi-on' https://infinitypv.com/products/heli-on

[3] M.T. Lloyd, C.H. Peters, A. Garcia, I.V. Kauvar, J.J Berry, M.O. Reese, M.D. McGehee, D.S Ginley, D.C. Olson, Influence of the hole-transport layer on the initial behavior and lifetime of inverted organic photovoltaics, Solar Energy Materials and Solar Cells, 95(5), (2011), 1382-1388.

[4] D.M. Tanenbaum, M. Hermenau, E. Voroshazi, M.T. Lloyd, Y. Galagan, B. Zimmermann, M. Hösel, H.F. Dam, M. Jørgensen, S.A. Gevorgyan, S. Kudret, The ISOS-3 inter-laboratory collaboration focused on the stability of a variety of organic photovoltaic devices, Rsc Advances, 2(3), (2012) 882893.

[5] J. Kettle, N. Bristow, D.T. Gethin, Z. Tehrani, O. Moudam, B. Li, E.A. Katz, G.A. dos Reis Benatto, F.C. Krebs, Printable luminescent down shifter for enhancing efficiency and stability of organic photovoltaics. Solar Energy Materials and Solar Cells, 144, (2016) 481-487.

[6] M. Jørgensen, J.E. Carlé, R.R. Søndergaard, M. Lauritzen, N.A. Dagnæs-Hansen, S.L. Byskov, T.R. Andersen, T.T. Larsen-Olsen, A.P. Böttiger, B. Andreasen, L. Fu, The state of organic solar cells-A meta analysis. Solar Energy Materials and Solar Cells, 119, (2013) 84-93. 
[7] S.A Gevorgyan, A.J. Medford, E. Bundgaard, S.B. Sapkota, H.F. Schleiermacher, B. Zimmermann, U. Würfel, A. Chafiq, M. Lira-Cantu, T. Swonke, M. Wagner, An inter-laboratory stability study of rollto-roll coated flexible polymer solar modules. Solar Energy Materials and Solar Cells, 95(5)(2011) 1398-1416.

[8] S.A. Gevorgyan, M.V. Madsen, H.F. Dam, M. Jørgensen, C.J. Fell, K.F. Anderson, B.C Duck, A. Mescheloff, E.A. Katz, A. Elschner, R. Roesch, Interlaboratory outdoor stability studies of flexible roll-to-roll coated organic photovoltaic modules: Stability over 10,000 h. Solar Energy Materials and Solar Cells, 116, (2013) 187-196.

[9] O. Haillant, D. Dumbleton, A. Zielnik, An Arrhenius approach to estimating organic photovoltaic module weathering acceleration factors. Solar Energy Materials and Solar Cells, 95(7), (2011) 18891895.

[10] O. Haillant, 2011. Accelerated weathering testing principles to estimate the service life of organic PV modules. Solar Energy Materials and Solar Cells, 95(5), pp.1284-1292.

[11] M.O. Reese, S.A Gevorgyan, M. Jørgensen, E. Bundgaard, S.R. Kurtz, D.C. Ginley, D.C. Olson, M.T. Lloyd, P. Morvillo, E.A. Katz, A. Elschner, Consensus stability testing protocols for organic photovoltaic materials and devices. Solar Energy Materials and Solar Cells, 95(5), (2011) 1253-1267.

[12] Kumar, P., Bilen, C., Vaughan, B., Zhou, X., Dastoor, P.C. and Belcher, W.J., 2016. Comparing the degradation of organic photovoltaic devices under ISOS testing protocols. Solar Energy Materials and Solar Cells, 149, pp.179-186.

[13] Waters, H., Bristow, N., Moudam, O., Chang, S.W., Su, C.J., Wu, W.R., Jeng, U.S., Horie, M. and Kettle, J., 2014. Effect of processing additive 1, 8-octanedithiol on the lifetime of PCPDTBT based Organic Photovoltaics. Organic Electronics, 15(10), pp.2433-2438.

[14] Corazza, M., Krebs, F.C. and Gevorgyan, S.A., 2014. Predicting, categorizing and intercomparing the lifetime of OPVs for different ageing tests. Solar Energy Materials and Solar Cells, 130, pp.99106.

[15] See InfinityPV for more details website https://infinitypv.com/

[16] Bristow, N. and Kettle, J., 2015. Outdoor performance of organic photovoltaics: Diurnal analysis, dependence on temperature, irradiance, and degradation. Journal of Renewable and Sustainable Energy, 7(1), p.013111.

[17] Kettle, J., Bristow, N., Sweet, T.K., Jenkins, N., dos Reis Benatto, G.A., Jørgensen, M. and Krebs, F.C., 2015. Three dimensional corrugated organic photovoltaics for building integration; improving the efficiency, oblique angle and diffuse performance of solar cells. Energy \& Environmental Science, 8(11), pp.3266-3273. 


\begin{tabular}{|l|l|l|l|l|l|}
\hline $\begin{array}{l}\text { Outdoor test } \\
\text { number }\end{array}$ & Date & $\begin{array}{l}\text { Median } \\
\text { irradiance } \\
\left(\mathrm{kW} / \mathrm{m}^{2}\right)\end{array}$ & $\begin{array}{l}\text { Median } \\
\text { Relative } \\
\text { Humidity }(\%)\end{array}$ & $\begin{array}{l}\text { Median } \\
\text { Temperature } \\
(\mathrm{K})\end{array}$ & $\mathrm{B}$ (63\%)(hours) \\
\hline 1 (dark) & Jan 2017 & $\mathrm{~N} / \mathrm{A}$ & $79 \%$ & $282 \mathrm{~K}$ & 480 \\
\hline 2 & July 2013 & $0.277(0.281)$ & $74 \%$ & $291 \mathrm{~K}$ & $352(428)$ \\
\hline 3 & July 2014 & $0.260(0.260)$ & $76 \%$ & $288 \mathrm{~K}$ & $368(703)$ \\
\hline 4 & June 2016 & $0.217(0.243)$ & $75 \%$ & $289 \mathrm{~K}$ & $228(732)$ \\
\hline
\end{tabular}

Table 1: Experimental data obtained from outdoor testing at Bangor University. Median irradiance, relative humidity and temperature over the testing period are shown and time taken for $63 \%$ of modules to reach the point of failure time are shown [B(63\%)]. For the latter, failure time is defined as $780 \%$ or (in brackets) T50\%. Note: The B(63\%) times for test 2-4 were calculated excluding nondaylight hours, so assumes only light-induced degradation of modules. B(63\%) times are equivalent and can be compared to $\eta$ in the Weibull 2-P PDF listed in equation 1.

\begin{tabular}{|l|l|l|l|l|}
\hline & $\begin{array}{l}\text { Dataset 1-D (all } \\
\text { DTU data) }\end{array}$ & $\begin{array}{l}\text { Dataset 2-D (just } \\
\text { R2R DTU data) }\end{array}$ & $\begin{array}{l}\text { Dataset 3-D (DTU } \\
\text { R2R +45/85 } \\
\text { data) }\end{array}$ & Dataset 4-D (BU) \\
\hline$\beta$ & 1.68 & 1.37 & 1.38 & 3.81 \\
\hline$\eta$ & 15 & 196 & 176 & 915 \\
\hline B & 375 & 46 & 166 & 140 \\
\hline$\Phi$ & 29 & 915 & 2785 & 3748 \\
\hline$\Phi / V ~$ & 0.10 & 3.24 & 9.87 & 13.29 \\
\hline B/H & 4.75 & 0.58 & 2.10 & 1.77 \\
\hline$\rho$ & 0.912 & 0.888 & 0.906 & 0.975 \\
\hline
\end{tabular}

Table 2: Fitted parameters obtained using mean likelihood estimation (MLE) for Dataset 1-4D for temperature-humidity analysis. $B$ is defined as the shape parameter, $\eta$ the scale parameter from the Weibull 2-p probability distribution in equation 1 . The values of $A, B$ and $\varnothing$ are the fitting parameters from the temperature-humidity model in equation 2 . The correlation coefficient, $\rho$, is shown to compare the 'fit' of the linear regression model for each dataset.

\begin{tabular}{|l|l|l|l|l|l|l|}
\hline & $\begin{array}{l}\text { Dataset 1-L } \\
\text { (all DTU } \\
\text { data) }\end{array}$ & $\begin{array}{l}\text { Dataset 2-L } \\
\text { (just R2R } \\
\text { DTU data) }\end{array}$ & $\begin{array}{l}\text { Data set 3- } \\
\text { L (DTU R2R } \\
\text { + BU data) }\end{array}$ & $\begin{array}{l}\text { Dataset 4-L } \\
\text { (BU data) - } \\
\text { using } \\
\text { sulphur } \\
\text { plasma }\end{array}$ & $\begin{array}{l}\text { Dataset 5-L } \\
\text { (BU data) } \\
\text { using } \\
\text { halogen } \\
\text { light } \\
\text { soaker- T80 }\end{array}$ & $\begin{array}{l}\text { Dataset 5-L } \\
\text { (BU data) - } \\
\text { using } \\
\text { halogen } \\
\text { light soaker } \\
- \text { T50 }\end{array}$ \\
\hline$n$ & 0.65 & 0.81 & 0.91 & 0.78 & 0.80 & 0.68 \\
\hline$\beta$ & 1.1 & 1.3 & 1.55 & 2.33 & 2.37 & 3.15 \\
\hline$\eta$ & 261 & 282 & 96 & 24 & 444 & 555 \\
\hline
\end{tabular}




\begin{tabular}{|l|l|l|l|l|l|l|}
\hline$\rho$ & 0.840 & 0.862 & 0.805 & 0.841 & 0.820 & 0.755 \\
\hline
\end{tabular}

Table 3: Fitted parameters obtained using mean likelihood estimation (MLE) for Dataset 1-5L for light degradation analysis. $B$ is defined as the shape parameter, $\eta$ the scale parameter from the Weibull 2$p$ probability distribution in equation 1. The values of $n$ is a fitting parameters from the inverse power law (IPL) model in equation 4. The correlation coefficient, $\rho$, is shown to compare the 'fit' of the linear regression model for each dataset.

\begin{tabular}{|l|l|l|l|l|l|l|}
\hline Test run & $\begin{array}{l}\text { Median } \\
\text { irradiance } \\
\text { to T80\% }\end{array}$ & $\begin{array}{l}\text { Experimental } \\
\eta-T 80 \%\end{array}$ & $\begin{array}{l}\text { Simulated } \\
\eta-T 80 \%\end{array}$ & $\begin{array}{l}\text { Median } \\
\text { irradiance } \\
\text { to T50\% }\end{array}$ & $\begin{array}{l}\text { Experimental } \\
\eta-T 50 \%\end{array}$ & $\begin{array}{l}\text { Simulated } \\
\eta-T 50 \%\end{array}$ \\
\hline Inverse Power law (IPL) \\
\hline July 2014 & 0.277 Sun & 352 & $397(+12 \%)$ & 0.281 Sun & 428 & $500(+16 \%)$ \\
\hline May 2015 & 0.260 Sun & 368 & $418(+13 \%)$ & 0.260 Sun & 501 & $527(+5 \%)$ \\
\hline June 2016 & 0.217 Sun & 228 & $\begin{array}{l}483 \\
(+115 \%)\end{array}$ & 0.243 Sun & 838 & $552(-35 \%)$ \\
\hline Temperature-Light (TL) model & \multicolumn{7}{l|}{} \\
\hline July 2014 & 0.277 Sun & 352 & $424(+20 \%)$ & 0.281 Sun & 428 & $652(+52 \%)$ \\
\hline May 2015 & 0.260 Sun & 368 & $442(+20 \%)$ & 0.260 Sun & 501 & $703(+40 \%)$ \\
\hline June 2016 & 0.217 Sun & 228 & $\begin{array}{l}498 \\
(+118 \%)\end{array}$ & 0.243 Sun & 838 & $732(-13 \%)$ \\
\hline
\end{tabular}

Table 4: A comparison of experimental values of versus simulated values of $\eta$ can be calculated for the three outdoor measurement campaign at T80\% and T50\% for the Inverse Power law (IPL) and Temperature Light (TL) model. For the IPL, dataset 5 and 6 was used for the fitting parameters (see table 3). With exception to June 2016, T80\% simulation, or values of $\eta$ are predicted to within $35 \%$. For the $T L$, whilst the relative prediction is slightly worse than the IPL model, the model provides a more robust technique for predicting light induced degradation at normal operational temperatures.

\begin{tabular}{|l|l|l|}
\hline & T80\% & T50\% \\
\hline$D$ & 4463 & 2923 \\
\hline$C$ & $3.6 e-5$ & 0.013 \\
\hline$n$ & 0.66 & 0.59 \\
\hline$\beta$ & 5.8 & 4.98 \\
\hline$\eta$ & 498 & 733 \\
\hline$\rho$ & 0.800 & 0.775 \\
\hline
\end{tabular}

Table 5: fitting parameters for the Temperature-Light (TL) relationship using the Weibull 2-p PDF. The values $C, D$ and $n$ are fitting parameters for equations 6 and 7 . Fitting parameters obtained for module degradation to T80\% and T50\%. The correlation coefficient, $\rho$, is shown to compare the 'fit' of the linear regression model for each dataset. 


\begin{tabular}{|l|l|l|l|l|l|}
\hline Test name & $\begin{array}{l}\text { Temperature } \\
(\mathrm{K})\end{array}$ & $\begin{array}{l}\text { Relative } \\
\text { Humidity } \\
(\%)\end{array}$ & $\begin{array}{l}\text { Irradiance } \\
\left(\mathbf{k W} / \mathbf{m}^{2}\right)\end{array}$ & AF & $\begin{array}{l}\text { Test hours } \\
\text { needed for 1 } \\
\text { year outdoor } \\
\text { simulation }\end{array}$ \\
\hline ISOS-D-1 & 298 & 50 & $\mathrm{n} / \mathrm{a}$ & 0.45 & 19393 \\
\hline ISOS-D-2 & 338 & 50 & $\mathrm{n} / \mathrm{a}$ & 2.00 & 4377 \\
\hline ISOS-D-3 & 338 & 85 & $\mathrm{n} / \mathrm{a}$ & 12.11 & 717 \\
\hline ISOS-L-2 & 338 & $\mathrm{n} / \mathrm{a}$ & 1 & 15.70 & 558 \\
\hline ISOS-L-3 & 358 & 50 & 1 & 24.70 & 355 \\
\hline
\end{tabular}

Table 6: Acceleration factors (AF) for ISOS-D and ISOS-L tests based upon the temperature-humidity model and temperature-light model, respectively. Included are the test hours required to simulate 1year outdoor performance in Bangor, Wales using each ISOS test.

\begin{tabular}{|c|c|c|c|c|c|}
\hline Location & $\begin{array}{l}\text { Mean } \\
\text { temperature } \\
\text { (K) }\end{array}$ & Mean RH (\%) & $\begin{array}{l}\text { Mean } \\
\text { Irradiance } \\
\left(\mathrm{kW} / \mathrm{m}^{2}\right)\end{array}$ & AF & $\begin{array}{l}\text { T80\% (measured or } \\
\text { simulated) }\end{array}$ \\
\hline $\begin{array}{l}\text { Bangor, Gwynedd } \\
\text { (June, 2014) }\end{array}$ & $289 \mathrm{~K}$ & 76 & 0.185 & $n / a$ & 41 days (measured) \\
\hline Madrid (June) & $294 K$ & 50 & 0.302 & 0.77 & 53 days (simulated) \\
\hline $\begin{array}{l}\text { Rio de Janiero } \\
\text { (June) }\end{array}$ & 294.5 & 77 & 0.242 & 2.11 & 19 days(simulated) \\
\hline $\begin{array}{l}\text { Bangor, Gwynedd } \\
\text { (Jan, 2015) }\end{array}$ & 280 & 83 & 0.081 & 0.57 & $\begin{array}{l}52 \text { days (measured) } \\
71 \text { days (simulated) }\end{array}$ \\
\hline
\end{tabular}

Table 7: simulated ageing of modules in different environmental conditions, relative the degradation measured in Bangor (June 2014). Module lifetime is simulated to be greater in wintertime due to lower irradiance, which is supported by experimental data 


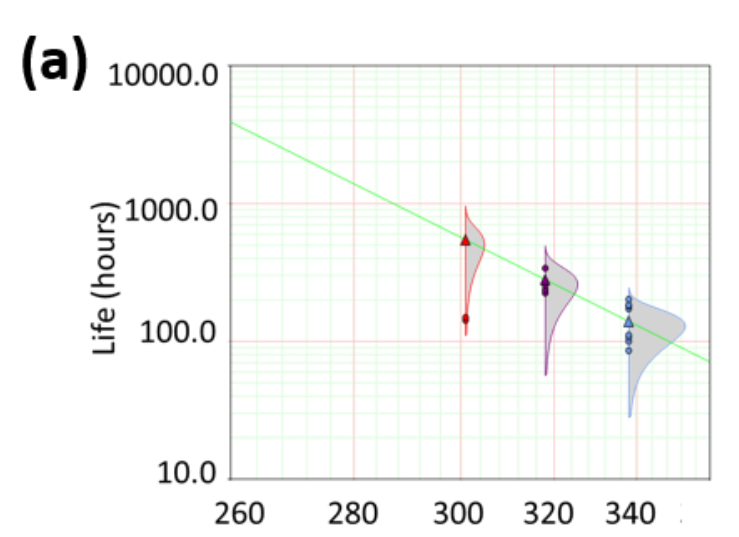

(b)

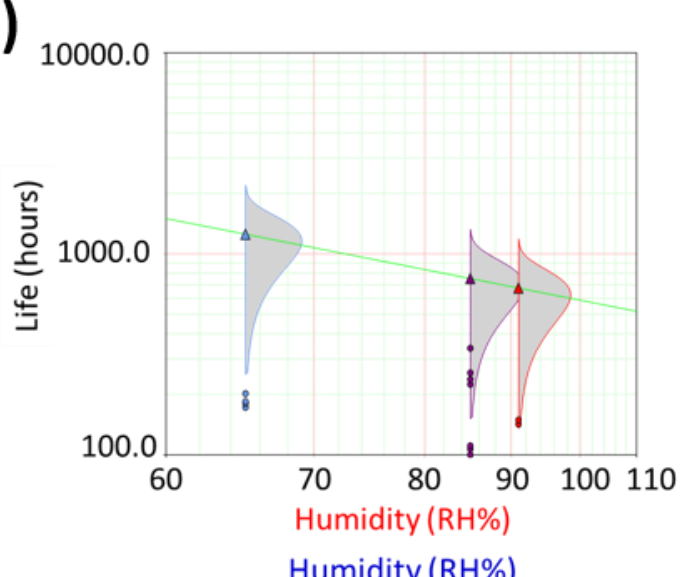

(c)

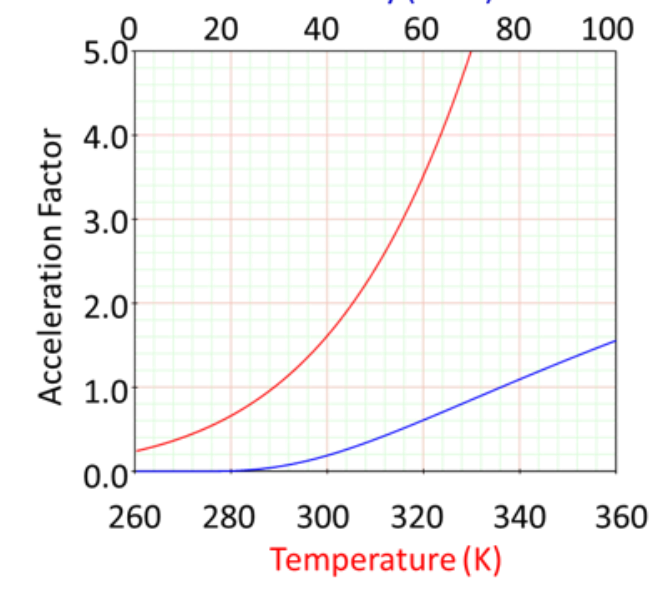

Figure 1: Regression line fitting for Dataset 3-D of the expected time of the solar cell to reach T80\% as a function of (a) relative humidity (\%) and (b) temperature (K). Included in (a) and (b) are the fitted probability distribution functions for each stress level. The Acceleration Factor (AF) as a function of temperature and RH humidity is shown in (c). 


\section{a)}
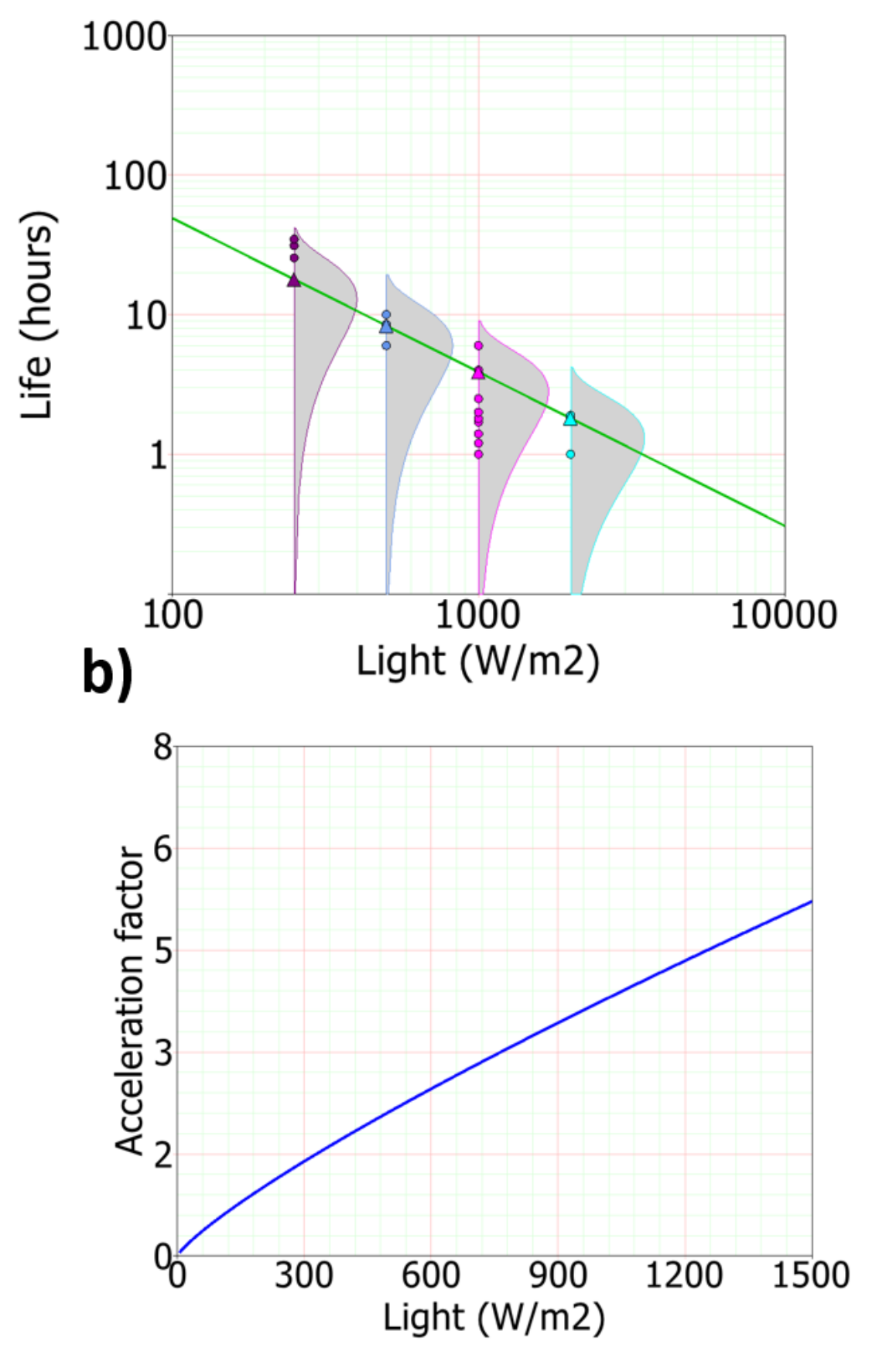

Figure 2: Regression line fitting of the (a) expected time for the OPV to reach to T80\% as a function irradiance level and (b) acceleration factor as a function of irradiance level for Dataset 4-L. Included in (a) are the fitted probability distribution functions for each stress level. 


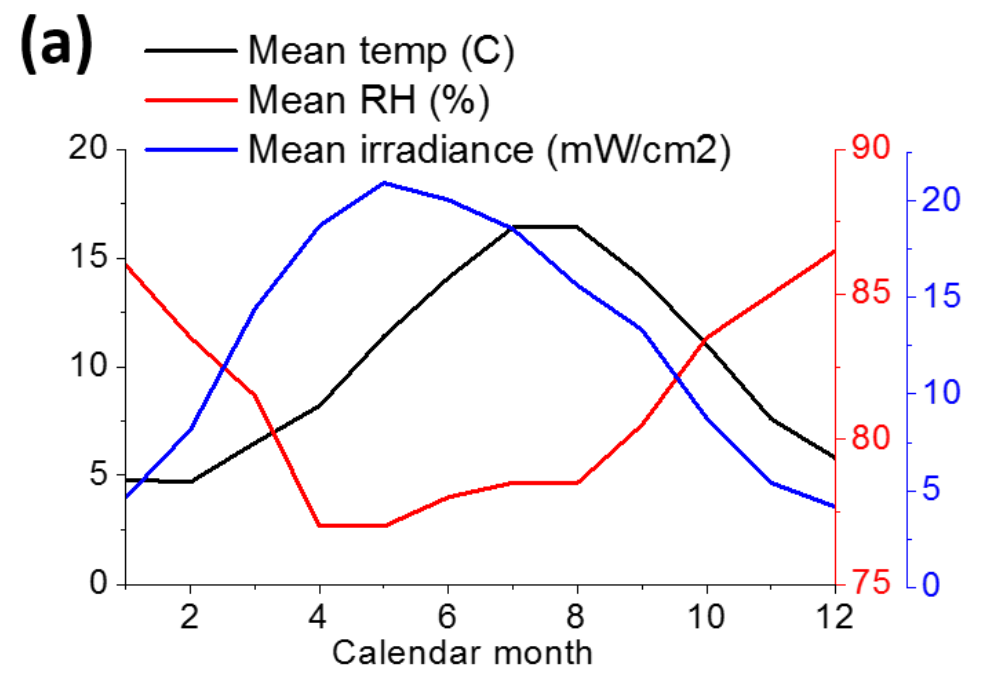

(b)

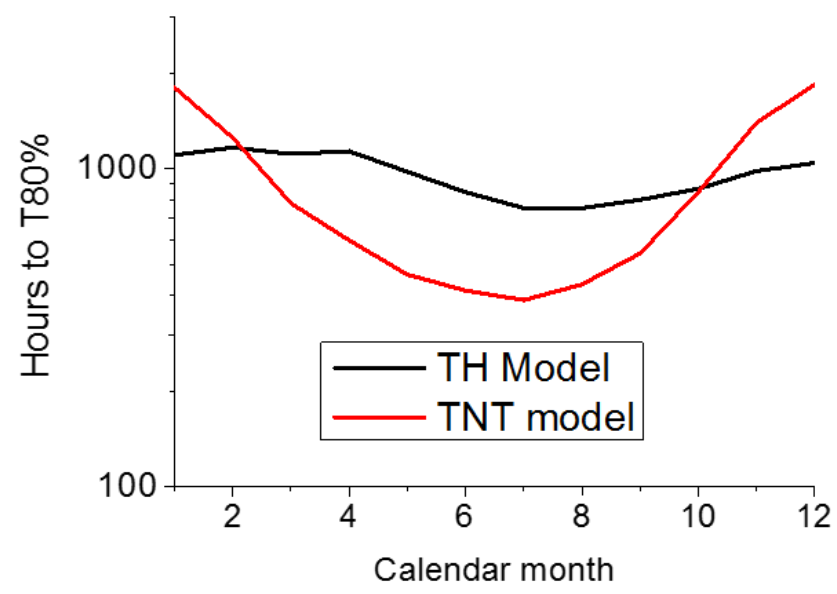

Figure 3: (a) Mean temperature, relative humidity (RH) and In-plane irradiance for Bangor, Gwynedd, UK over a full calendar year and (b) Impact on expected life to T80\% as a function of calendar month as predicted by the temperature-humidity (TH) model and Temperature-light (TL) model 